This item was submitted to Loughborough's Research Repository by the author.

Items in Figshare are protected by copyright, with all rights reserved, unless otherwise indicated.

\title{
Blending poly(butylene succinate) with poly(lactic acid): ductility and phase inversion effects
}

\section{PLEASE CITE THE PUBLISHED VERSION}

http://dx.doi.org/10.1016/j.eurpolymj.2015.08.029

\section{PUBLISHER}

(c) Elsevier

\section{VERSION}

AM (Accepted Manuscript)

\section{PUBLISHER STATEMENT}

This work is made available according to the conditions of the Creative Commons Attribution-NonCommercialNoDerivatives 4.0 International (CC BY-NC-ND 4.0) licence. Full details of this licence are available at: https://creativecommons.org/licenses/by-nc-nd/4.0/

\section{LICENCE}

CC BY-NC-ND 4.0

\section{REPOSITORY RECORD}

Deng, Yixin, and Noreen L. Thomas. 2015. "Blending Poly(butylene Succinate) with Poly(lactic Acid): Ductility and Phase Inversion Effects". figshare. https://hdl.handle.net/2134/19027. 


\title{
Blending Poly(butylene succinate) with Poly(lactic acid): Ductility and Phase Inversion Effects
}

\section{Y Deng and N L Thomas*,}

Department of Materials, Loughborough University, Ashby Road,

Loughborough, Leicestershire, LE11 3TU, UK

*N.L.Thomas@lboro.ac.uk, Tel. +44(0)1509223334

\begin{abstract}
Synergistic effects of blending two bio-based, bio-degradable polymers, poly(butylene succinate) (PBS) and poly(lactic acid) (PLA) are investigated. A series of melt-blended compounds were prepared at PBS/PLA weight ratios of 0/100, 10/90, $20 / 80,40 / 60,60 / 40,80 / 20$ and 100/0. Thermal properties, crystallinity, melt viscosities, mechanical properties and phase morphology were studied. There was found to be a dramatic improvement in ductility, over $250 \%$ elongation-to-break, with as little as 10 weight \% of PBS added. This was shown to be due to a co-continuous phase morphology, which was determined by the relative viscosities of the components.
\end{abstract}

Keywords: poly(lactic acid); poly(butylene succinate); blend; co-continuous phase 


\section{Introduction}

The recent surge of interest in bio-plastics has come from growing concern about the disposal of plastic waste and the need to find alternatives to landfill - for which biodegradable polymers offer a possible solution. Coupled with this is the requirement to find replacements for fossil fuel feed-stocks, and hence the focus on polymers that are derived from renewable resources, such as plant-based materials. Poly(lactic acid) (PLA) is one of the most commercially successful of the bio-derived polymers and is widely used in biomedical applications because of its biocompatibility and also in packaging and other short-life disposable products [1].

PLA has the structure, $\left[\mathrm{CH}\left(\mathrm{CH}_{3}\right) \mathrm{COO}\right]_{\mathrm{n}}$, and is synthesised from renewable resources via lactic acid fermentation [2]. Although there are a number of methods for producing high molecular weight PLA, the method that is the most successful, and is therefore used commercially, is by ring-opening polymerisation of the lactide, which is a cyclic dimer consisting of two lactic acid molecules [3]. Lactic acid contains an asymmetric carbon atom and therefore it occurs in two optically active configurations ( $L$ and $D$ ). These two configurations can form three different lactides: L-lactide (a dimer of L-lactic acid), D-lactide (a dimer of D-lactic acid) and mesolactide (a dimer of $\mathrm{L}$ - and D-lactic acid). The extent to which the polymer will crystallise is governed by its content of L-, D- and meso-lactide: the more optically pure polymers have higher chain symmetry and therefore higher crystallinities. PLA resin containing $50-93 \%$ of L-lactic acid is amorphous, due to the imperfections introduced by the D-lactic acid [3]. However, PLA with more than $93 \%$ of L-lactic acid is semi-crystalline.

A typical glass transition temperature $\left(T_{g}\right)$ for PLA is around $57^{\circ} \mathrm{C}$, although this will vary slightly depending on the crystallinity and molecular weight of the polymer. Hence at room temperature PLA is a hard, brittle solid with mechanical properties not dissimilar to those of polystyrene [1, 4]. A number of approaches are commonly taken to improve the toughness of brittle polymers, including plasticisation, incorporation of impact modifiers and melt blending. All of these methods have been employed to modify the properties of PLA $[4,5]$.

Poly(butylene succinate) (PBS) is another aliphatic, biodegradable polyester. It is synthesized by polycondensation reaction of 1,4 butanediol and succinic acid [6] and has the molecular structure shown in Figure 1.

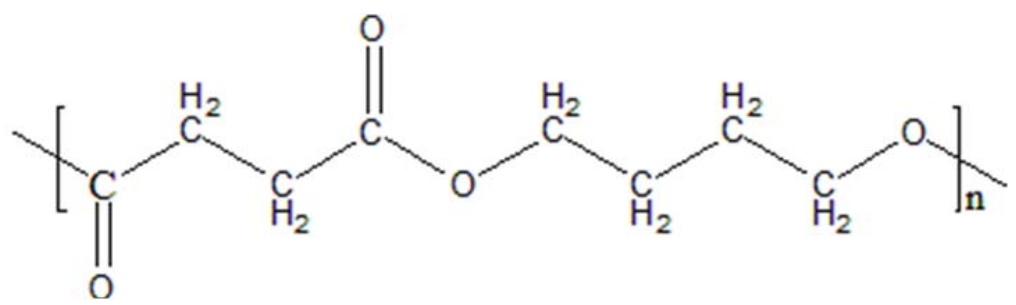

Figure 1. Molecular structure of PBS. 
PBS is of particular interest because of its mechanical properties. It is a crystalline polymer with a glass transition temperature of about $-35^{\circ} \mathrm{C}$ and a melting point around $114^{\circ} \mathrm{C}[6,7]$. Hence, at room temperature it behaves as a ductile polymer and may exhibit elongation-to-break in excess of $300 \%$, depending on molecular weight [6].

Melt blending of PBS with PLA would appear to be an ideal route for improving properties of these polymers because of their complementarity: increasing the toughness of PLA and the stiffness of PBS. A key factor in determining the success or otherwise of blending of two polymers, as for all alloy systems, is the extent to which the two materials are mutually miscible. Although it might be considered that for high molecular weight polymers mixing is unlikely because very small entropies of mixing would always dominate, it is found that specific interactions, such as polar attractions, can play a role in developing mutual miscibility. This has been found to be true for bioplastics because they contain polar groups that can give rise to stronger interactions [5].

In the case of blending of PBS and PLA, the extent of miscibility is not entirely clear. Park and Im [8] investigated phase behaviour and morphology of melt blended PLA and PBS and calculated the Flory-Huggins interaction parameter,$X$, to be -0.15 . The negative value of $X$ indicates that PLA and PBS are fully miscible, although these authors also reported that at a PBS content in excess of $40 \%$ there was significant crystallization-induced phase separation. Bhatia et al [9] used modulated DSC to measure $T_{g}$ and reported that the $T_{g}$ of PLA did not change with addition of PBS, and hence concluded that the blends were immiscible, although they found that rheological results showed compatibility when the PBS content was below 20 weight \%. On the other hand, Jompang et al [10] investigated morphology of PLA/PBS blends by scanning electron microscopy (SEM) from which they concluded that PBS was miscible with PLA up to an addition level of 10 weight $\%$. However, Wu and co-workers [11] reported that PBS and PLA are thermodynamically incompatible. From SEM and optical micrographs they found that the blends showed an immiscible phase structure, with a phase inversion point of the blend system at a PLA/PBS ratio of $50 / 50$.

Results reported in the literature for increasing the toughness of PLA on blending with PBS are somewhat disappointing. For example, Bhatia et al [9] found no improvement in the ductility (strain-to-break) of PLA/PBS blends until the PBS content had reached 90 weight \%. A similar result was reported by Lee and Lee [12], who investigated blends of PLA with poly(butylene succinate adipate) (PBSA). However, these authors did find a significant improvement in impact strength on addition of 10-20 weight \% PBSA but at higher PBSA concentrations impact values dropped down to those of PLA until 100\% PBSA was reached. Hassan et al [13] found that strain-to-break of PLA/PBS blends increased gradually with increasing PBS content, although high ductilities were only reached at PBS levels in excess of 80 weight $\%$. Some other authors have investigated the incorporation of 
compatibilizer to improve the toughness of PBS/PLA blends. Wang et al [14] added dicumyl peroxide (DCP) to PBS/PLA blends and observed an improvement in notched Izod impact strength in the presence of the DCP. They also found that the PBS/PLA $20 / 80$ blend had a very high elongation at break of $250 \%$, although this property was not significantly influenced by the incorporation of DCP. Shibata et al [15] blended poly(butylene succinate-co-l-lactate) (PBSL) with PLA and compared these blends with those of PBS/PLA. Mechanical properties of both sets of blends were quite similar over the whole composition range, indicating that the structural difference between PBS and PBSL had surprisingly little effect on the compatibility with PLA.

In the current paper it is shown that dramatic increases in ductility of PLA/PBS blends can be achieved at low addition levels of PBS ( 10 weight \%) and this is the first paper to demonstrate this effect. It is shown to be dependent on the phase morphology obtained. It is investigated how a co-continuous phase morphology is influenced by the relative viscosities of the components.

\section{Experimental}

\subsection{Materials}

Poly(lactic acid) (PLA) (Ingeo ${ }^{\text {TM }}$ 4032D) was supplied by Natureworks LLC (Minetonka, MN, USA). 4032D is a crystallisable grade of PLA with an L-lactide content of about 98.6 weight $\%$. Its melting point is in the range $160-180^{\circ} \mathrm{C}$ and its density is $1.24 \mathrm{~g} / \mathrm{cm}^{3}$. Its weight average molecular weight $\left(M_{w}\right)$ was determined by gel permeation chromatography (GPC) and found to be $94 \times 10^{3} \mathrm{~g} / \mathrm{mol}$.

Poly(butylene succinate) was obtained from Ire Chemicals Ltd, Korea. This is a commercial grade of polymer designated, EnPol G4560-M. It has a glass transition temperature $(\mathrm{Tg})$ of about $-35^{\circ} \mathrm{C}$ and a melting point of around $115^{\circ} \mathrm{C}$. The density of the polymer is $1.26 \mathrm{~g} / \mathrm{cm}^{3}$. GPC analysis was carried out to determine the molecular weight of this polymer using chloroform as the solvent and polystyrene standards. The weight average molecular weight $\left(M_{w}\right)$ was found to be $88 \times 10^{3} \mathrm{~g} / \mathrm{mol}$.

\subsection{Sample Preparation}

PLA was blended with PBS at different composition ratios (PBS/PLA: 0/100, 20/80, $40 / 60,60 / 40,80 / 20$ and 100/0 by weight). The two components were first dried in a vacuum oven at $65^{\circ} \mathrm{C}$ for 24 hours to remove the moisture absorbed. Then they were melt blended in a counter-rotating mixer (Haake Rheomix OS) in order to promote dispersive and distributive mixing. The total input of sample weight was $58 \mathrm{~g}$ and mixing was carried out at $175^{\circ} \mathrm{C}$ for 10 mins with a constant rotor speed of $60 \mathrm{rpm}$. After mixing, the blends were hot pressed at a temperature of $190^{\circ} \mathrm{C}$. Samples were preheated for 15 minutes and then compressed for 3 minutes under a pressure of 15 tons, followed by cooling to room temperature over a further period of 3 minutes 
under a pressure of 5 tons. Sheets were produced with thicknesses of $1 \pm 0.10 \mathrm{~mm}$ and tensile bars were cut from these.

\subsection{Characterization and Testing}

\subsubsection{Differential Scanning Calorimetry (DSC)}

The melting and crystallization behaviour, as well as the miscibility of the blends, were investigated using differential scanning calorimetry (DSC). Measurements were performed using a DSC Q200 (TA Instruments, USA) fitted with an auto-sampler and mechanical cooler. Samples of approximately 10 15 mg were cut from the polymer samples and sealed in aluminium pans before being loaded into the chamber. The samples were heated from $20^{\circ} \mathrm{C}$ to $200^{\circ} \mathrm{C}$ in a nitrogen atmosphere at a rate of $10^{\circ} \mathrm{C} / \mathrm{min}$. Data was analysed using the TA universal analysis software package. At least 3 specimens were tested at each composition ratio.

The amount of overall crystallinity, $X_{c}$, was calculated using Equation 1.

$$
X_{C}=\left(\frac{\Delta H_{m}-\Delta H_{c}}{\Delta H_{100}}\right) \times 100 \%
$$

Where $\Delta H_{m}$ is the enthalpy of melting; $\Delta H_{c}$ is the enthalpy of cold crystallization; and $\Delta H_{100}$ is the enthalpy of fusion for $100 \%$ crystalline polymer. For PLA, $\Delta H_{100}=93 \mathrm{~J} / \mathrm{g}$ while for PBS $\Delta H_{100}=110.3 \mathrm{~J} / \mathrm{g}$.

\subsubsection{Capillary Rheometry}

The shear viscosities of both PBS and PLA at $175^{\circ} \mathrm{C}$ were determined using a flowmaster (ROSAND) capillary rheometer. Pressure was measured at eight different ram velocities. The twin-bore barrel contained a die of length/diameter ratio of 16 and a 'zero length' die to generate a Bagley correction and hence eliminate end-pressure effects. Ram velocities for PLA were varied between $1000 \mathrm{~mm} / \mathrm{s}$ and $200 \mathrm{~mm} / \mathrm{s}$ and those of PBS between $2000 \mathrm{~mm} / \mathrm{s}$ and $400 \mathrm{~mm} / \mathrm{s}$. The higher velocities were required for PBS because of its low melt viscosity.

\subsubsection{Tensile Testing}

Tensile properties of the samples were measured using a Universal testing machine (LLOYD Instruments). The compression moulded sheets were cut into dumbbell shapes with a gauge length of $25 \mathrm{~mm}$, width of $4 \mathrm{~mm}$ and thickness of $1 \mathrm{~mm}$. The crosshead speed used was $10 \mathrm{~mm} / \mathrm{min}$. In order to precisely determine the threshold ratio at which the samples exhibited high ductility, samples over a wider range of composition ratios were tested. The PBS/PLA ratios were as follows: 0/100, 10/90, 20/80, 30/70, 40/60, 42/58, 44/56, 46/54, 48/52, 50/50, 60/40, 70/30, 80/20, 100/0 by weight. For each composition ratio, at least 8 specimens were tested. 


\subsubsection{Morphology}

\subsubsection{Atomic Force Microscopy (AFM)}

Atomic force microscopy (Veeco Explorer) was employed to investigate the topography of the surfaces of the blends to determine their morphology. A noncontact scanning mode with constant force was used. Only the surface topography of the hot pressed samples was measured because the cross sections were found to be too rough to be analysed. The phase pictures of the two polymers are not included in this paper as the hardness difference between the two polymers could not be sufficiently clearly determined.

\subsubsection{Optical Microscopy}

Optical microscopy was used to observe the crystalline morphology of the PBS/PLA sheets and hence to study the dispersion of the two components. Samples were observed between crossed polars in a Leica ${ }^{\circledR}$ DM LM binocular transmitted light microscope equipped with a FP82 hot stage and a FP90 control unit. For hot stage microscopy, samples of roughly $0.1 \mathrm{~mm}$ thickness from compression moulding flashings were placed on a glass slide and covered with a glass slip. The birefringent structures were observed at room temperature and then the samples were heated to $190^{\circ} \mathrm{C}$ using the hot stage facility at a rate of $10^{\circ} \mathrm{C} / \mathrm{min}$. This allowed observation of the cold crystallisation and melting behaviours.

\subsubsection{Scanning electron microscopy (SEM)}

The morphology of the fracture surfaces of the PBS/PLA blends was examined using a scanning electron microscope equipped with a field emission gun (FEGSEM, LEO 1530 VP). The samples were gold coated before examination. The FEGSEM was operated at a voltage of $5 \mathrm{kV}$ and both the transverse and longitudinal sections of the tensile fracture surfaces were observed.

\section{Results and Discussion}

\subsection{Crystallinity and Thermal Analysis}

DSC traces of PBS/PLA blends are shown in Figure 2. When heated from $20^{\circ} \mathrm{C}$ to $200^{\circ} \mathrm{C}$, neat PLA went through the following thermal transitions: the glass transition $\left(56.0 \pm 1.2^{\circ} \mathrm{C}\right)$, cold crystallization $\left(102.2 \pm 0.8^{\circ} \mathrm{C}\right)$ and melting $\left(170.8 \pm 0.4^{\circ} \mathrm{C}\right)$. On the other hand, neat PBS exhibited a cold crystallization peak at $\left(99.6 \pm 0.02^{\circ} \mathrm{C}\right)$ and a melting peak at $\left(116.7 \pm 0.2^{\circ} \mathrm{C}\right)$. 


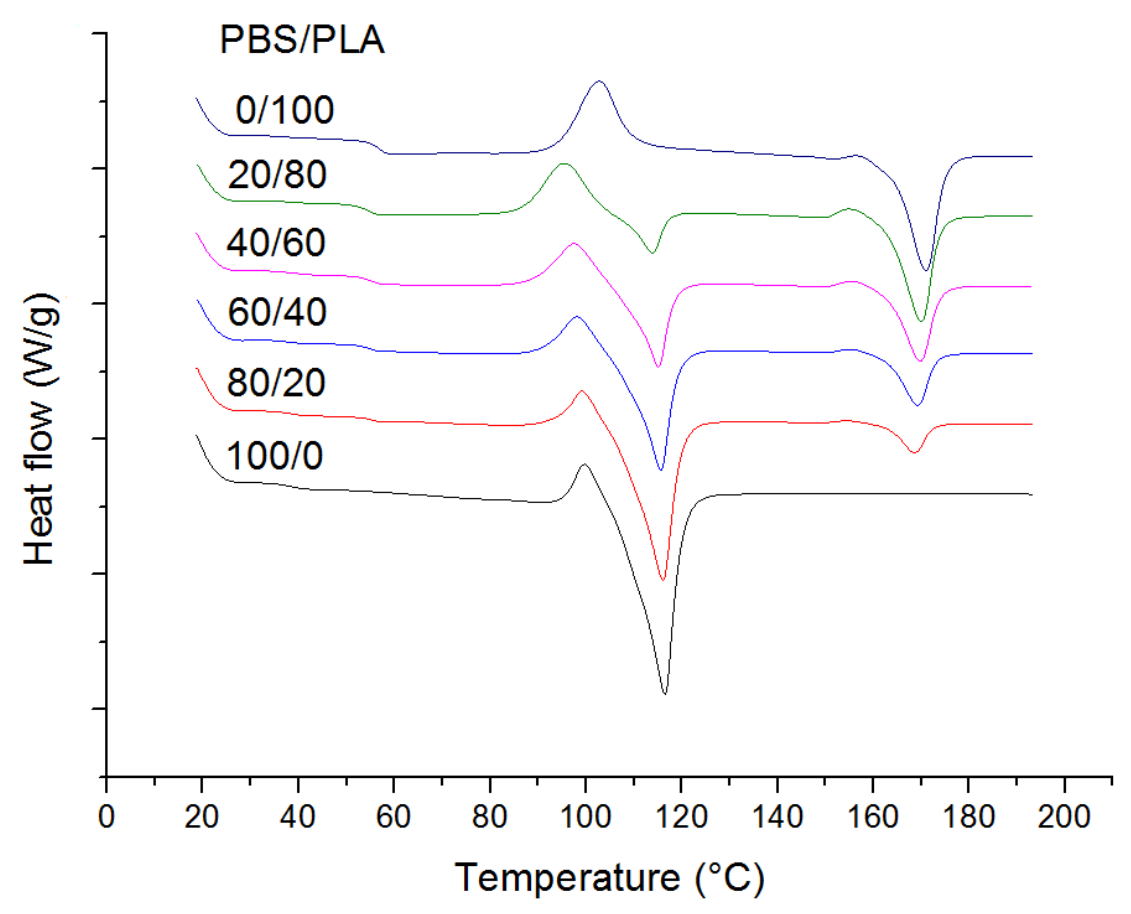

Figure 2. DSC traces of PBS/PLA blends

Due to the overlapping of the cold crystallization peaks of PBS and PLA, it is difficult to calculate the crystallinity of PBS and PLA separately. Different heating rates, which were as low as $1^{\circ} \mathrm{C} / \mathrm{min}$ and as high as $50^{\circ} \mathrm{C} / \mathrm{min}$, were tried to separate the cold crystallization peaks, but all failed. Therefore, in order to give an assessment of the crystallization behaviour, in this paper it is assumed that for PBS the ratio of its cold crystallization enthalpy to its melting enthalpy is independent of the composition ratio of the blend. For pure PBS, this ratio is found from the DSC data to be $0.107 \pm$ 0.02 , so this ratio was applied to the data from the other compositions.

Based on this assumption, the crystallinities of PBS and PLA were calculated from the DSC data and are shown plotted as a function of composition in Figure 3. The crystallinity of pure PLA is zero and this is also confirmed by the results of optical microscopy (see section 3.3.4.2). On blending PBS with PLA, the crystallinity of both PLA and PBS is increased. When 20 wt $\%$ PBS is blended with PLA, the crystallinity of PLA is increased significantly to about $16 \%$. As discussed by Yokohara and Yamaguchi [16], this is presumably because molten PBS, or impurities in the PBS, can act as crystallization nuclei for PLA. 


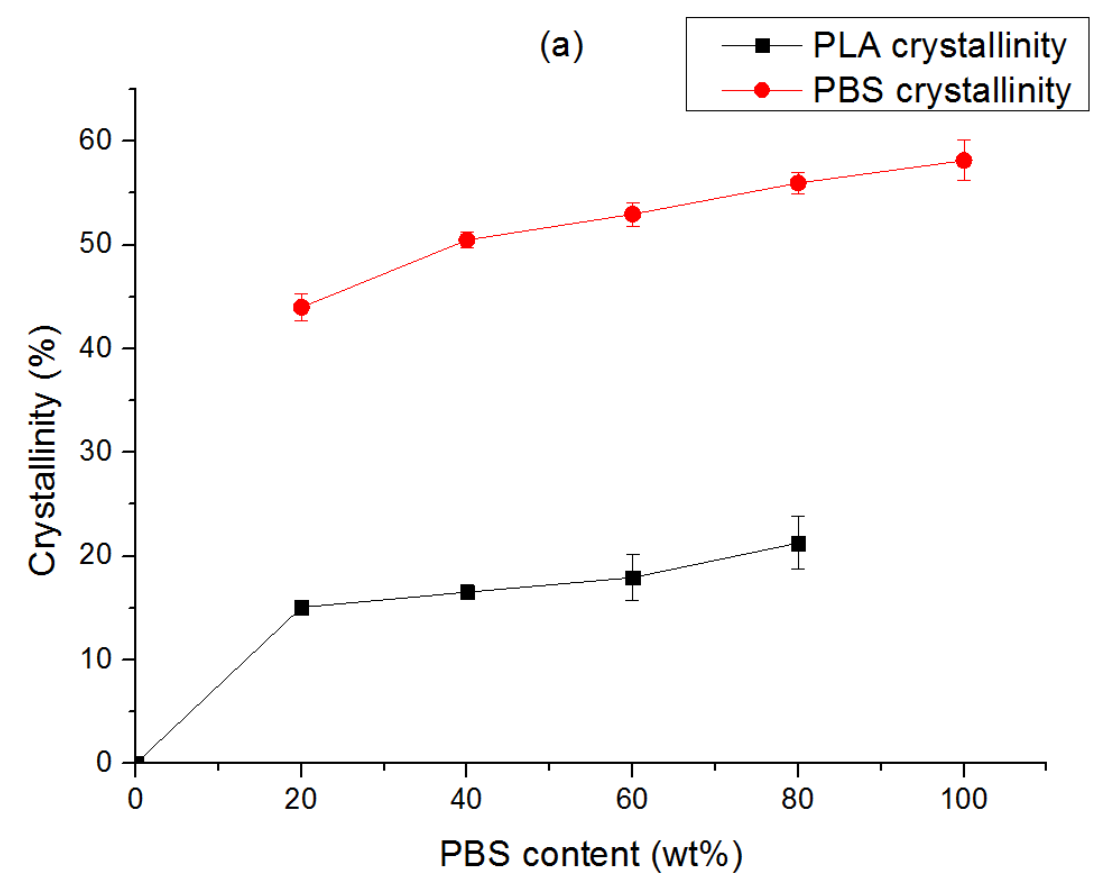

Figure 3. Crystallinities of PBS and PLA

Table 1 shows the DSC results of the glass transition temperature $\left(T_{g}\right)$ of PLA on increasing the content of PBS. The $T_{g}$ for pure PLA is $56.0^{\circ} \mathrm{C}$, which decreases to $53.3^{\circ} \mathrm{C}$ when PBS is present in the blend at 20 weight \%. However, with increasing PBS content, it then rises again to $54.2^{\circ} \mathrm{C}$. These results demonstrate that PBS is not miscible with PLA even at $20 \mathrm{wt} \%$ of PBS. According to the rule of mixing, if the amorphous part of the PBS is miscible with the amorphous part of the PLA, there should be a shift in glass transition temperature according to the Fox equation [17]:

$$
1 / T_{g}=\omega(P B S) / T_{g}(P B S)+\omega(P L A) / T_{g}(P L A)
$$

In equation (2) $\mathrm{T}_{\mathrm{g}}$ is the glass transition temperature of the blend in $\mathrm{K} ; T_{g}(P B S)$ is the glass transition temperature of PBS, which is $235 \mathrm{~K} ; T_{g}(P L A)$ is the glass transition temperature of PLA, which is $329 \mathrm{~K} ; \omega(P B S)$ is the weight fraction of amorphous PBS in the total amorphous region; $\omega(P L A)$ is the weight fraction of amorphous PLA in the total amorphous region. When PBS is $20 \mathrm{wt} \%, \omega(P B S)$ is 0.14 and $\omega(P L A)$ is 0.86 . Hence, using equation (2), the $T_{g}$ of the blend was calculated to be $38.6^{\circ} \mathrm{C}$, which does not match with the experimental results in which $T_{g}=53.3 \pm 0.8^{\circ} \mathrm{C}$ (Table 1). Therefore, PBS and PLA are not miscible to any substantial degree.

Table 1. Glass transition temperatures of the blends with increasing PBS content

\begin{tabular}{|c|c|c|c|c|c|c|}
\hline PBS content $(\mathrm{wt} \%)$ & 0 & 20 & 40 & 60 & 80 & 100 \\
\hline $\mathrm{T}_{g}\left({ }^{\circ} \mathrm{C}\right)$ & $56.0 \pm 1.2$ & $53.3 \pm 0.8$ & $54.2 \pm 1.8$ & $54.2 \pm 1.6$ & $54.2 \pm 1.8$ & $\mathrm{~N} / \mathrm{A}$ \\
\hline
\end{tabular}


However, the small but significant drop in $T_{g}$ of the PBS/PLA 20/80 blend does indicate that PBS has some limited miscibility with PLA at $20 \mathrm{wt} \%$ PBS. On increasing the PBS content, the $T_{g}$ values of the blends are always higher than the $T_{g}$ of the PBS/PLA 20/80 blend but lower than the $T_{g}$ of pure PLA. This result suggests that the miscible content reduces as the PBS content increases.

\subsection{Shear Viscosity}

Capillary Rheometry was used to determine the melt viscosities of PBS and PLA at $175^{\circ} \mathrm{C}$, at a number of different volumetric flow rates. The shear rate dependence of the viscosities of PBS and PLA is plotted in Figure 4, from which it can be seen that both melts obey a power law model, as shown in equation (3), where $\eta$ is viscosity, $\dot{\gamma}$ is shear strain rate and $\mathrm{n}$ is the power law exponent.

$$
\eta=\eta_{0} \dot{\gamma}^{(n-1)}
$$

It is seen from Figure 4 that the power law relationships for the two polymer melts are as follows:

For PBS: $\eta_{P B S}=383 \dot{\gamma}^{-0.223}$

For PLA: $\eta_{P L A}=10619 \dot{\gamma}^{-0.467}$

The shear strain rate for PBS and PLA when mixed in the Haake is calculated from the Newtonian equivalent expression [18], as given in equation (4) below.

$$
\dot{\gamma}=16 \pi N \frac{\beta^{2}}{\left(1+\beta^{2}\right)\left(\beta^{2}-1\right)} \approx \frac{2 \pi N}{\ln (\beta)}
$$

In equation (4), $N$ is the rotor speed and $\beta$ is the ratio of the wall radius $\left(R_{e}\right)$ to the rotor radius $\left(R_{1}\right)$. For the Haake rheometer, $N$ is $60 \mathrm{rpm}$, which is 1 revolution per second, and $R_{e}$ and $R_{1}$ are $20 \mathrm{~mm}$ and $17.5 \mathrm{~mm}$ respectively. Hence, the shear strain rate in the Haake is calculated to be $47 \mathrm{~s}^{-1}$. Therefore, during mixing the viscosities of PBS and PLA are found to be 162 Pa.s and 1759 Pa.s, respectively.

These results agree well with the data of Yokohara et al [19], who also found that the viscosities of PLA were significantly higher than those of PBS.

In this study, the melt viscosities of only the individual polymers (PLA and PBS) have been measured at the processing temperature of the Haake mixer of $175^{\circ} \mathrm{C}$. This is because (as discussed in section 3.5) it is the ratio of the viscosities of the individual polymers that determines the polymer volume fraction at which a co-continuous phase will be formed. 


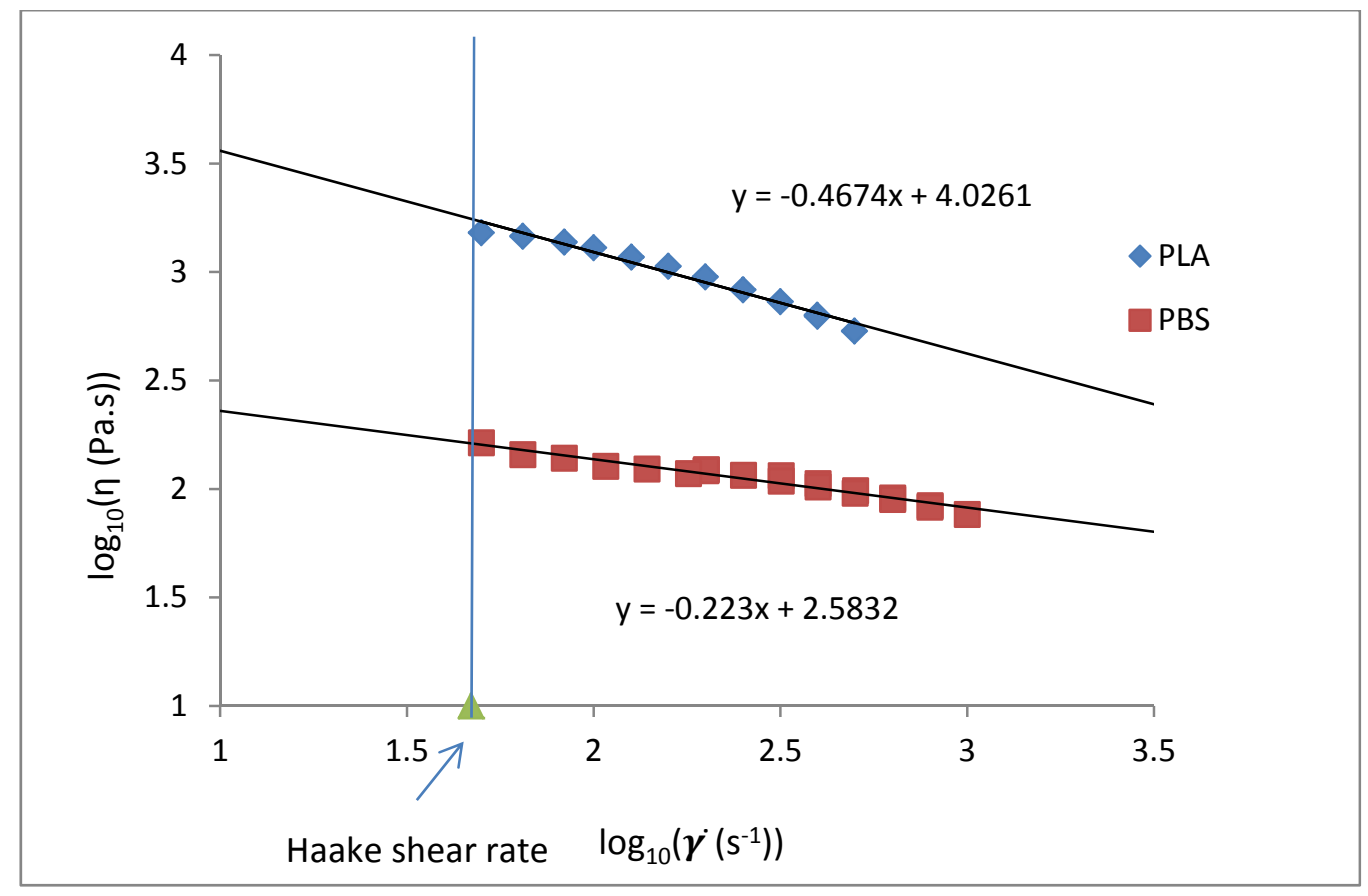

Figure 4. Shear viscosity $(\eta)$ versus shear strain rate $(\dot{\gamma})$ for PBS and PLA at $175^{\circ} \mathrm{C}$

\subsection{Mechanical properties}

The results of Young's modulus and tensile strength of the various blends are plotted as a function of PBS content in Figures 5 and 6 respectively. From these plots it can be seen that both Young's modulus and tensile strength decrease with increasing concentration of PBS in the blend. This result is what is expected on adding a ductile, flexible polymer to a rigid, brittle polymer. It is seen that for Young's modulus, the decreasing trend is quite linear. The trend for Young's modulus is expected to fall somewhere between the predictions from the parallel and series models, as represented in equations (5) and (6) respectively. Here $E_{1}$ and $E_{2}$ are the moduli of components 1 and 2 while $E_{b}$ is the modulus of the blend, and $\varphi_{1}$ and $\varphi_{2}$ are the volume fractions of components 1 and 2 .

Parallel Model

$$
E_{b}=\varphi_{1} E_{1}+\varphi_{2} E_{2}
$$

Series Model

$$
E_{b}=\frac{E_{1} E_{2}}{\left(\varphi_{1} E_{2}+\varphi_{2} E_{1}\right)}
$$

These two models represent the limits for the phase separated blends. The parallel model is the case where the higher modulus component is the continuous phase and represents the upper bound, whereas the series model is the case in which the higher modulus component is dispersed in the lower modulus continuous phase and represents the lower bound. 


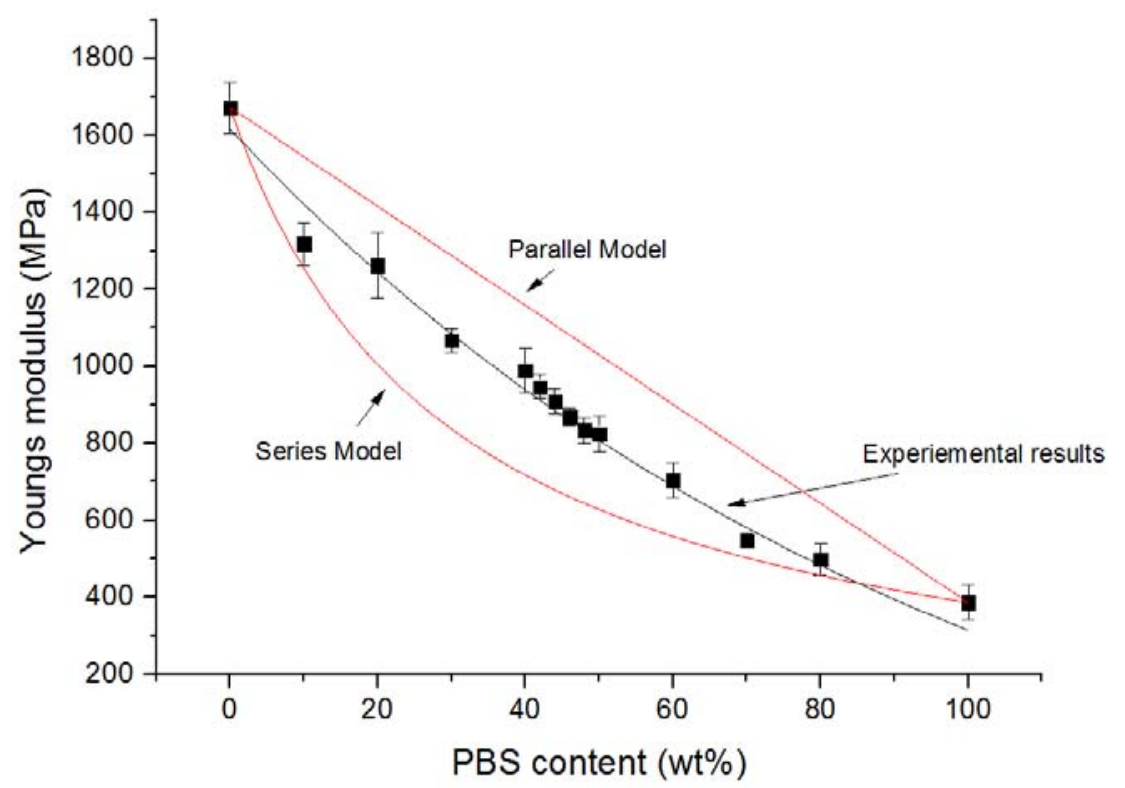

Figure 5. Effect of PBS content on Youngs modulus of the blend

The modulus of PLA is $1672 \mathrm{MPa}$ and that of PBS is $387 \mathrm{MPa}$. From Figure 5 it is found that the experimental data for Young's modulus are located in the range between the upper and lower bounds. This indicates that although PBS and PLA are not miscible, PBS is compatible with PLA. At 70 weight\% PBS and above, the Young's modulus of the blend approaches the series model, indicating that PBS is the continuous phase and the higher modulus component, PLA, is dispersed within the PBS.

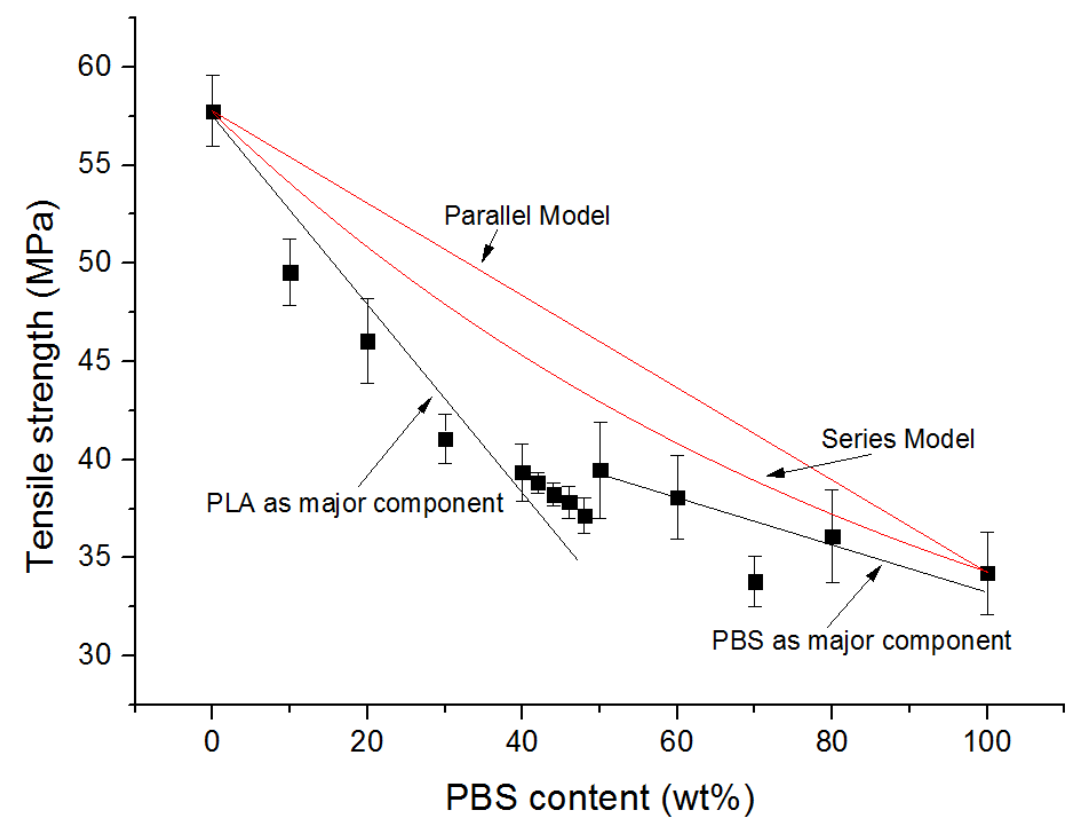

Figure 6. Effect of PBS content on the Tensile Strength of the blend 
Tensile strength results are plotted in Figure 6 . In this case it is clear that the measured values fall below those predicted by both the parallel and series models. It is seen that as the PBS content is increased to 40 weight \%, there is a steep linear reduction in tensile strength implying that, in this composition regime, the strength is disproportionately affected by the weaker PBS component. However, beyond this region, there is a more gradual drop in strength until the value for pure PBS is reached.

Figure 7 is a plot of the results for elongation-to-break as a function of PBS content. These data gave an unexpected result, in that it was found that on addition of only 10 weight $\%$ of PBS, a very ductile response was observed. For blends with PBS content between 10 and 40 weight \%, measured values of elongation-to-break ( $270 \%$ to $340 \%$ ) were in excess of those found for pure PBS. This result suggests that in the composition range 10 to 40 weight\%, PBS has formed a co-continuous phase, presumably very finely dispersed, and thus is having such an influence over the ductility of the blends.

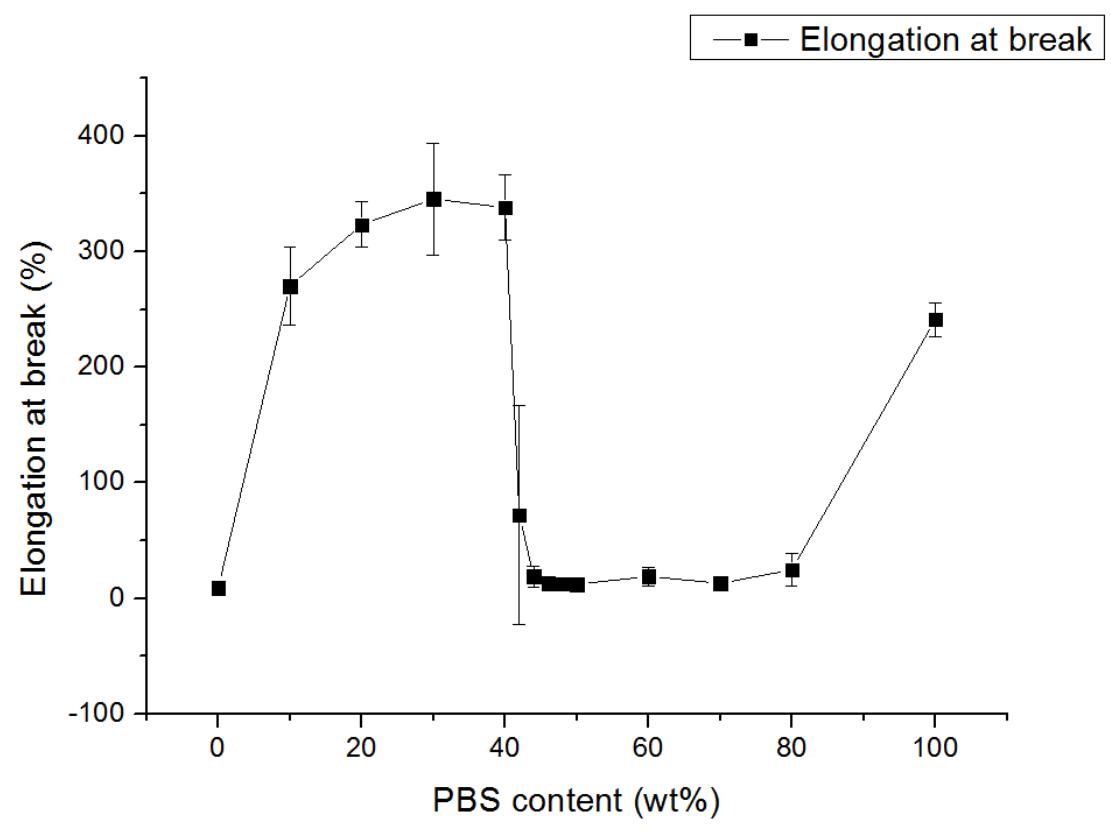

Figure 7. Effect of PBS content on the Elongation-to-break of the blend

It is also seen from both Figure 7 that when the content of PBS is increased above 40 weight \%, then there is a dramatic drop in the ductility of the blends back down to values of elongation-to-break around $12 \%$ to $19 \%$. These results imply that there is a change in morphology at this point. When PLA becomes the minor component, it will no longer be able to form the continuous phase and so it becomes dispersed in the PBS matrix. The ductility results imply that there is not good adhesion between the two components in this case. 


\subsection{Morphology}

\subsubsection{Atomic Force Microscopy (AFM)}

AFM was used to produce 3D images of the surfaces of the blend samples. Figure 8 shows the topography of the blends from a square of the surface measuring $2500 \mathrm{x}$ $2500 \mathrm{~nm}$ from a series of samples with increasing PBS/PLA ratio.

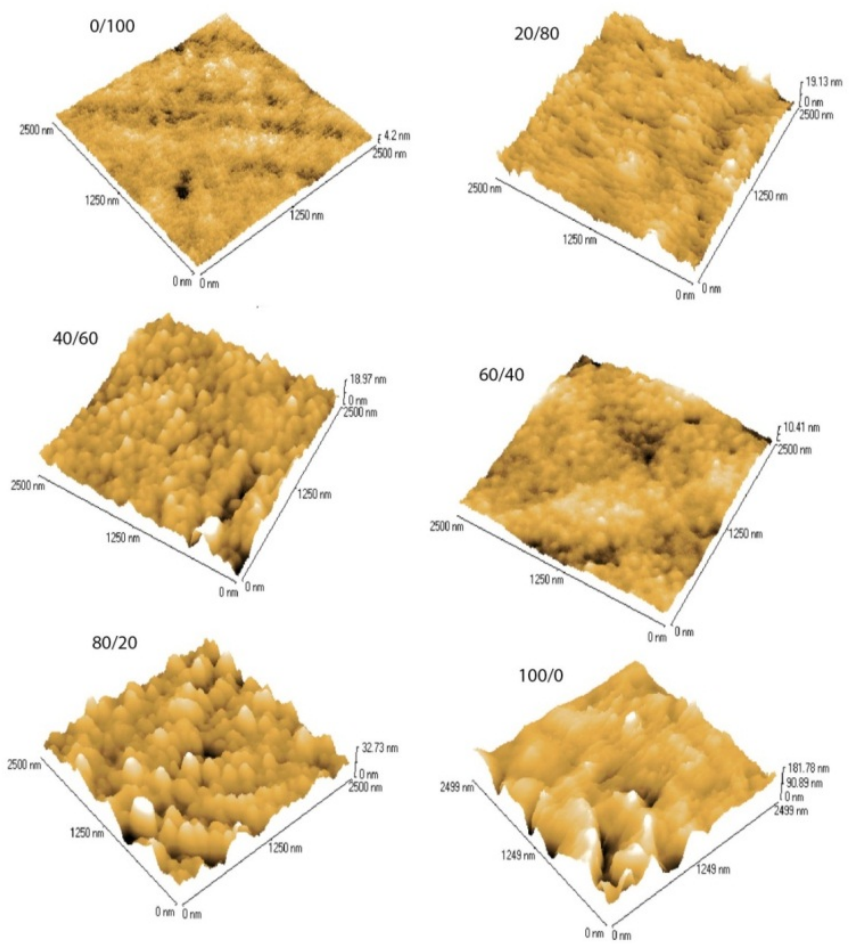

Figure 8. AFM 3D images of PBS/PLA blends

It can be seen from Figure 8 that the pure PLA sample has the smoothest surface and the surface topography becomes generally rougher with increasing PBS content. The roughest surface is that of pure PBS, where the peak height difference is 182 $\mathrm{nm}$. This is attributed to the highly crystalline nature of this sample. In the case of the PBS/PLA blends at ratios of $20 / 80,40 / 60,60 / 40$ and $80 / 20$, there is seen to be phase separation because the interface between the peaks and flat amorphous area is clearly defined. When the PBS content is higher than that of PLA, more flaws can be observed, which are indicated by dark areas on the surface. When the PBS content is lower than that of PLA, the surface morphology looks quite uniform and continuous. The PBS/PLA 20/80 blend seems to have the most continuous phase topography with PBS dispersing in fibril form in the PLA matrix.

\subsubsection{Optical Microscopy}

Optical micrographs were taken from a series of PBS/PLA blends using polarised light. These images are shown in Figure 9. PLA, being amorphous is black, whereas crystalline PBS is birefringent and therefore bright. 

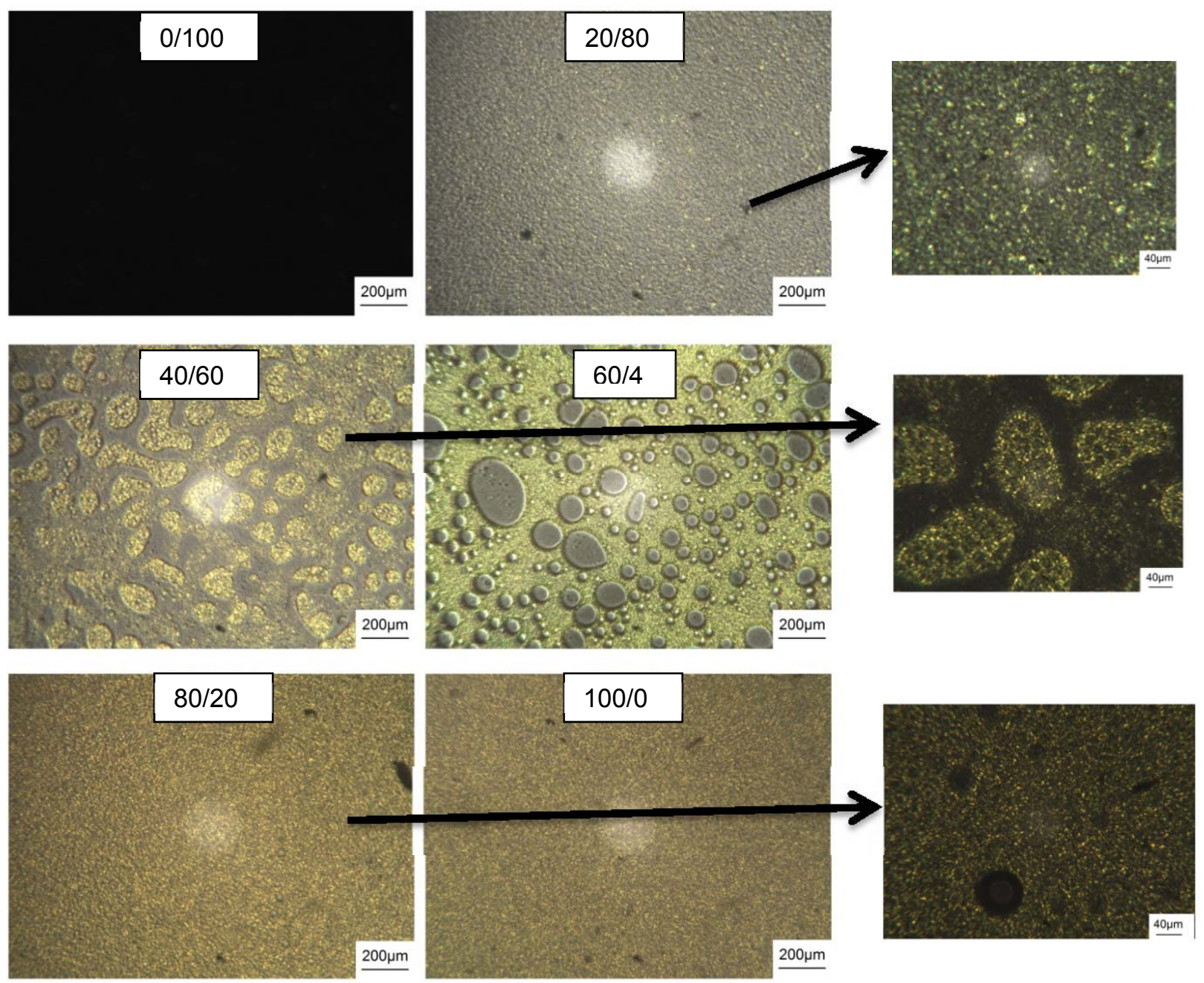

Figure 9. Optical Micrographs of PBS/PLA Blends using Crossed Polars

The images from polarised light optical microscopy show that there is phase separation in all four blends. The image of the $20 / 80$ blend shows that the PBS is very well dispersed in the PLA and there is evidence from the magnified image (insert) that PBS forms a continuous phase even at this very low level, suggesting a co-continuous phase structure. This fine, uniform morphology accounts for the very good ductility at this composition ratio. Similarly there is evidence of a co-continuous phase structure when PBS is present at 40 weight $\%$. This morphology can be more clearly seen in the inserted magnified image in which some PLA droplets are dispersed inside the PBS domains, again explaining why the 40/60 blend has such good ductility.

However, when the PBS content is increased to 60 weight $\%$, only a PBS continuous phase can be seen in the image, with PLA droplets of various sizes dispersed in the PBS matrix. For the $80 / 20$ blend there are much finer droplets of PLA in the PBS matrix although there are still some coarser ones amongst them. 
Optical micrographs from the hot stage microscope are shown in Figure 10. These micrographs were taken at a temperature of $180^{\circ} \mathrm{C}$.

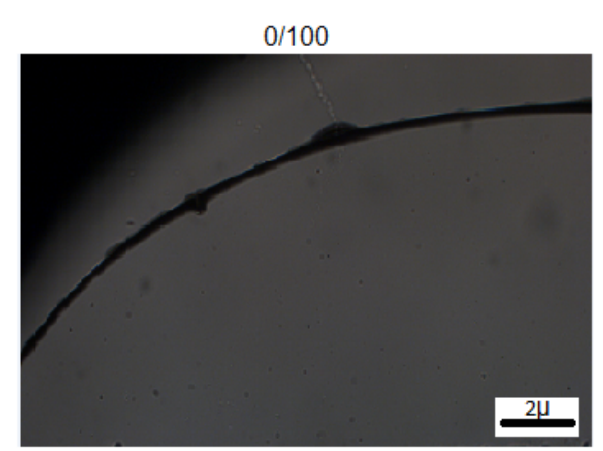

$40 / 60$

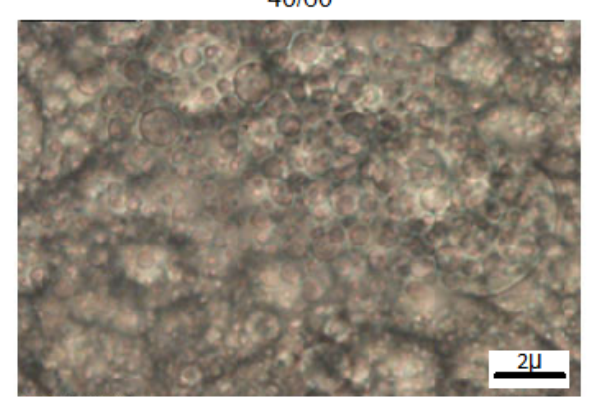

$80 / 20$

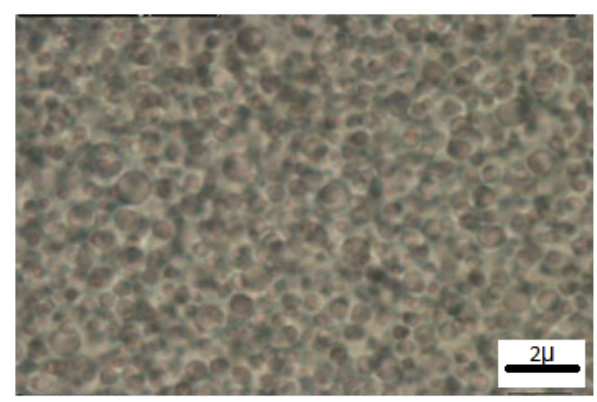

$20 / 80$

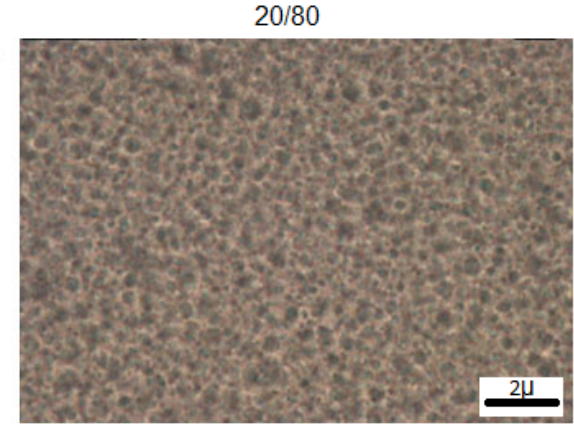

$60 / 40$

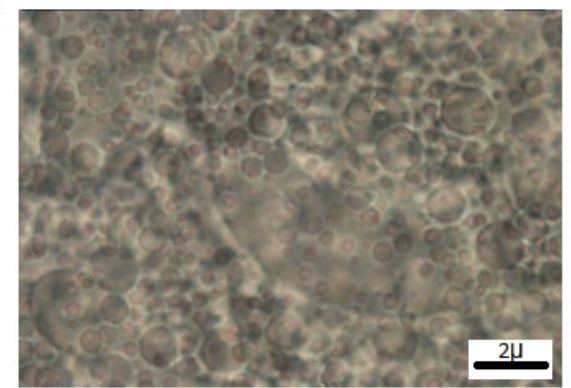

$100 / 0$

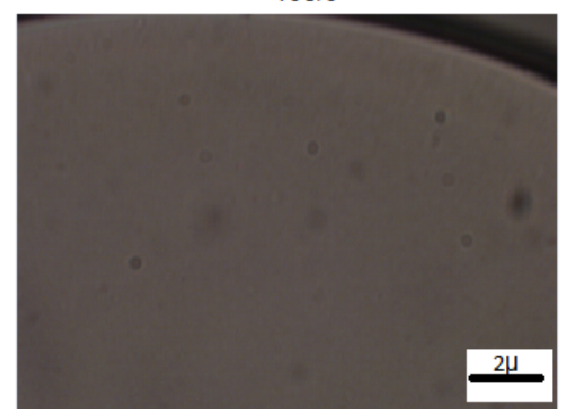

Figure 10. Hot-stage Optical Micrographs of PBS/PLA Blends at $180^{\circ} \mathrm{C}$

These micrographs confirm that phase separation is found in all blends and also show that PBS is able to form a continuous phase when it is present at only 20 weight $\%$. When the PBS is at 40 weight \%, the co-continuous phase structure can be more distinctly seen with some PLA droplets dispersed in PBS. The reason for this is that PBS has a much lower melt viscosity and thus it is easier for PBS to percolate through the structure while PLA tends to remain as droplets due to its high melt viscosity. During mixing, PBS cannot break down the PLA particles, so the dispersion of PLA is non-uniform and there is a large variation in size of the PLA domains.

\subsubsection{Scanning Electron Microscopy}

Scanning Electron Micrographs of the series of blends are shown in Figure 11. 
$0 / 100$

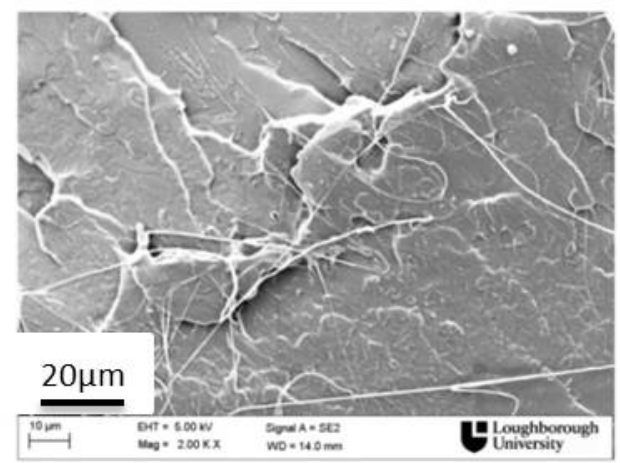

$40 / 60$

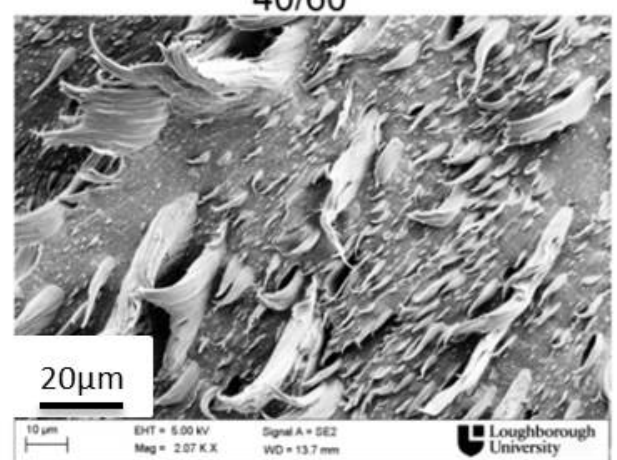

$80 / 20$

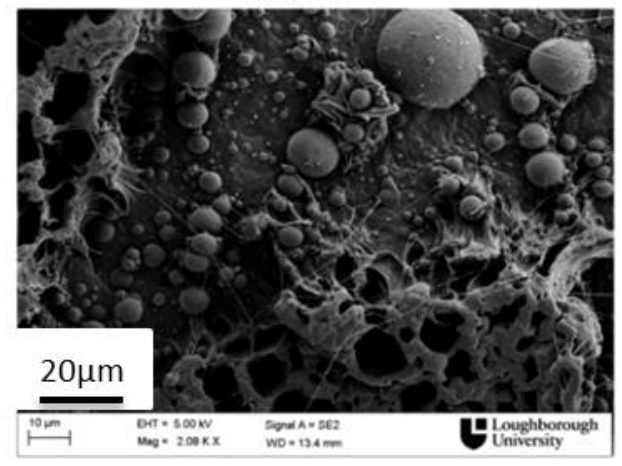

$20 / 80$

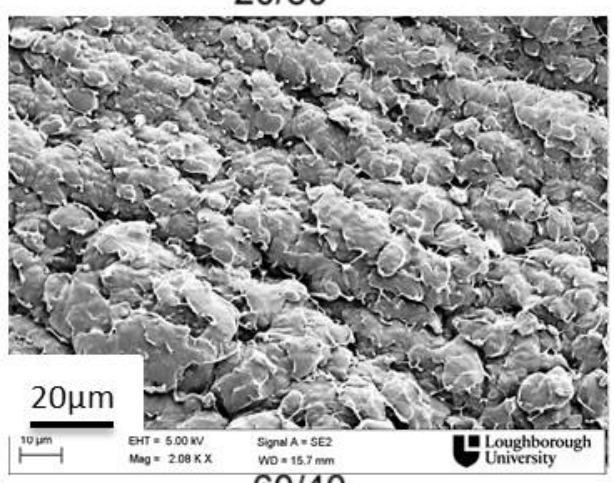

$60 / 40$

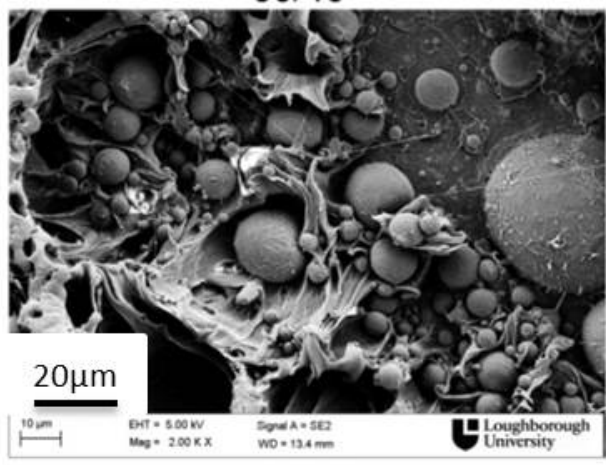

$100 / 0$

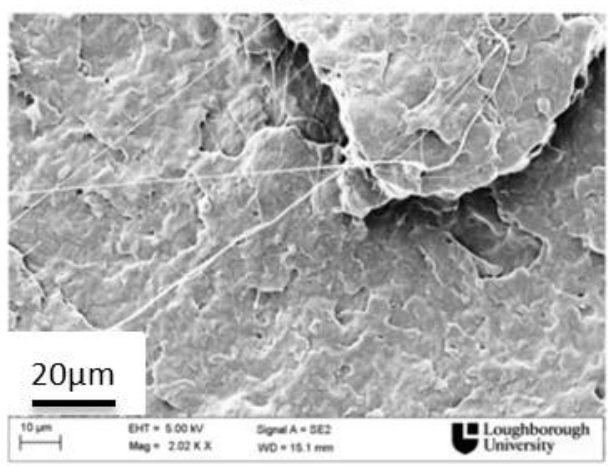

Figure 11. Scanning Electron Micrographs of Fracture Surfaces of PBS/PLA Blends

These scanning electron micrographs are fracture surfaces from the tensile testing experiments. The pure PLA sample has a flat featureless fracture surface typical of brittle failure. The 20/80 PBS/PLA sample has a finely dispersed two phase structure with tiny fibrils drawn from the surface, which is evidence of ductility. This is more obvious in the micrograph for the $40 / 60$ blend in which it can be clearly seen that the PBS formed a very thin continuous phase which deformed and broke after the PLA continuous phase, giving rise to the highly ductile behaviour. However, at higher PBS/PLA ratios, where PBS is the sole continuous phase, there is brittle failure because the PLA is present as poorly dispersed spheres of a wide range of sizes from sub-micron to tens of microns. Where the morphology changes from two cocontinuous phases to a PBS matrix with PLA as the dispersed phase, this is the point at which the ductility drops. 


\subsection{Discussion of Phase Structure and Viscosity Ratio}

The phase morphology of a polymer blend is a key factor determining its mechanical and physical properties. It is usually the case for immiscible blends that the major component will form the continuous phase in which the minor component is dispersed - often as spherical particles but sometimes as fibrils, depending on the polymer flow behaviour during processing. However, in addition to volume fraction, the continuous phase is determined by the melt viscosities of the components. Low viscosity and high volume fraction are the two factors leading to phase continuity. In some extreme cases, a component with very low melt viscosity can form a continuous phase even at very low volume fraction, as observed by Shur and Ranby when blending PVC with ethylene copolymers [20].

An empirical relationship [21-23] that gives guidance as to the formation of a continuous phase is shown in equation (7), where $\varphi_{1}$ and $\varphi_{2}$ are the volume fractions of components 1 and 2 , and $\eta_{1}$ and $\eta_{2}$ are the respective shear viscosities at the processing temperature and shear rate.

$$
\frac{\varphi_{1}}{\varphi_{2}}=\frac{\eta_{1}}{\eta_{2}}
$$

According to this equation, when $\eta_{1} / \eta_{2}>\varphi_{1} / \varphi_{2}$, continuity of component 2 is expected with component 1 forming the dispersed phase. However, when $\eta_{1} / \eta_{2}=\varphi_{1} / \varphi_{2}$, then component 1 should form a co-continuous phase along with component 2.

The shear viscosities of PBS (component 1) and PLA (component 2) at the processing temperature of $175^{\circ} \mathrm{C}$ and shear strain rate of $47 \mathrm{~s}^{-1}$ were found to be 162 and 1759 Pa.s respectively (section 3.2). Given that the density of PBS is $1.26 \mathrm{~g} / \mathrm{cm}^{3}$ while that of PLA is $1.25 \mathrm{~g} / \mathrm{cm}^{3}$, it is assumed that the volume fraction of each component is about equal to its weight fraction. Hence the threshold for formation of a co-continuous phase structure is when $\varphi_{\mathrm{PBS}} / \varphi_{\mathrm{PLA}}=0.092$. Thus when the PBS concentration reaches 8.4 weight $\%$, there is expected to be a change in morphology to a co-continuous phase structure.

The model of Metelkin and Blekht [24] has also been applied to confirm the morphology change of the blend. This model is represented by equations (8) and (9), where $\lambda=\eta_{1} / \eta_{2}$ and $\phi_{2}$ is the inversion point of component 2 (PLA).

$$
\begin{aligned}
\phi_{2} & =\frac{1}{1+\lambda F(\lambda)} \\
F(\lambda) & =1+2.25 \log \lambda+1.81(\log \lambda)^{2}
\end{aligned}
$$

From the capillary rheometer results, $\lambda=0.092, F(\lambda)=0.612$ and $\phi_{2}=0.947$. Hence the inversion point at which PBS forms a co-continuous phase is 5.3 weight $\%$. 
Together, these two models predict that the inversion point of PBS/PLA is between 5.3 weight $\%$ to 8.4 weight $\%$.

To further confirm this prediction, another 6 batches of PBS/PLA (from 0 weight $\%$ of PBS to 10 weight $\%$ of PBS) were produced at the same processing conditions and tested to measure the elongation at break as shown in Figure 12. The results of elongation at break also show the threshold of ductility of the blends changes significantly in the range between 6 weight $\%$ to 8 weight $\%$.

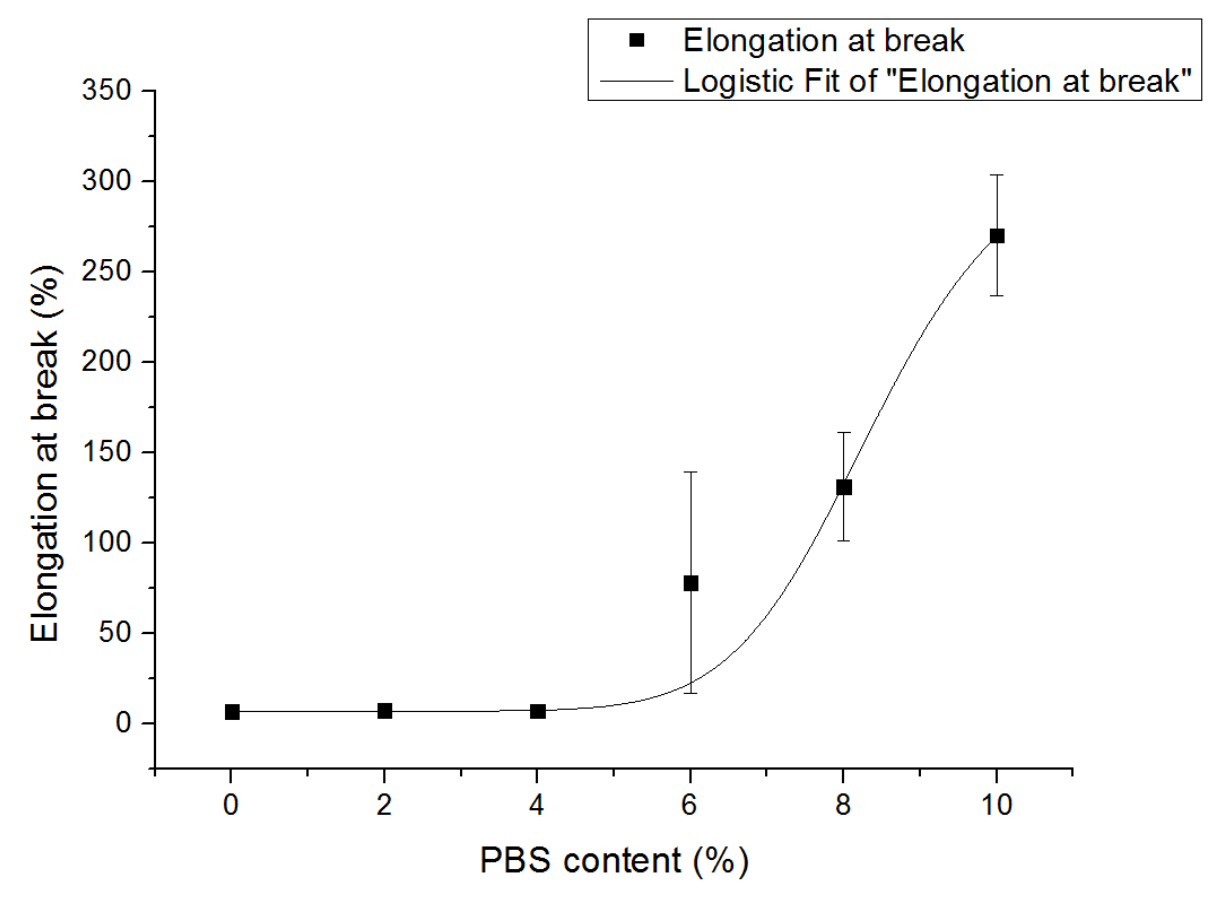

Figure 12. Effect of PBS content on the Elongation-to-break of the blend

This result agrees with the results found for tensile testing, when for the 10/90 PBS/PLA blend elongation-to-break was up at $270 \%$. Also the result is further confirmed in Figure 13, which shows SEM images from the longitudinal fracture surfaces of samples of PBS/PLA compositions of 10/90 and 20/80. These morphologies are finely dispersed, fibrillar co-continuous two phase structures. 

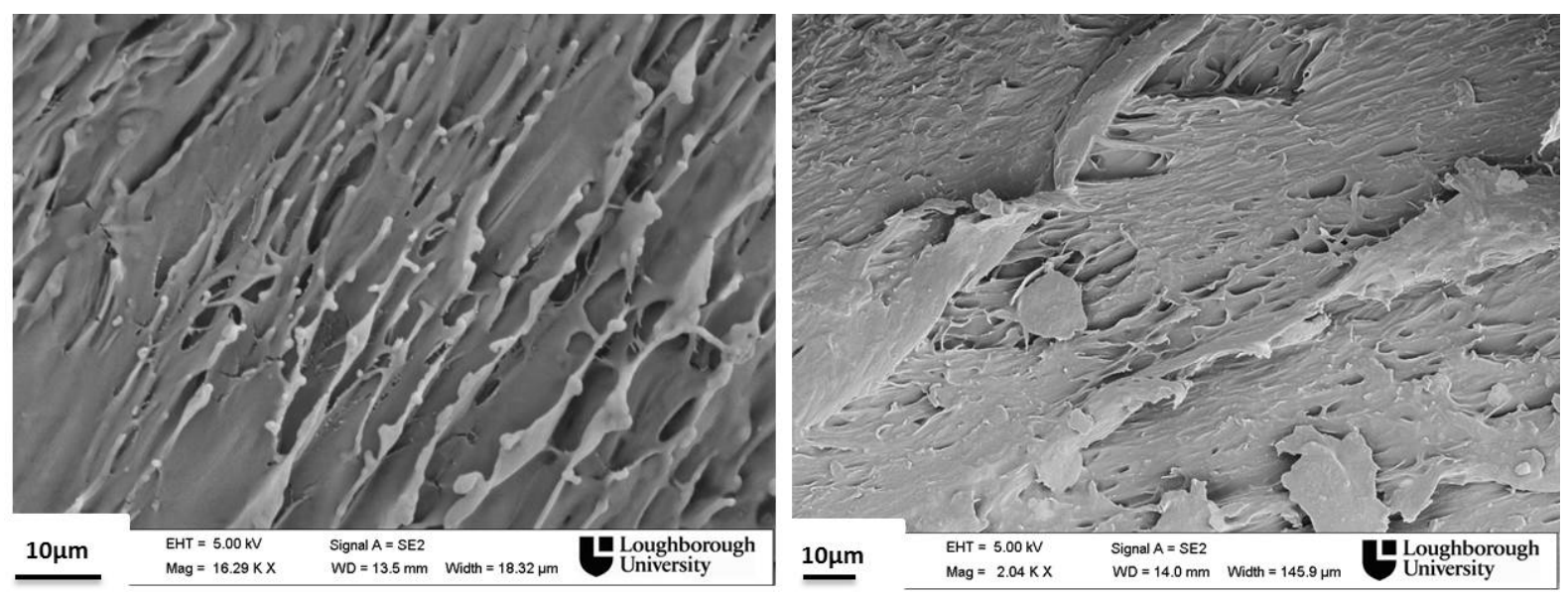

Figure 13. Scanning Electron Micrographs of 10/90(left) and 20/80 (right) Longitudinal Fracture Surfaces

These results agree with the work of Yokohara et al [19], who studied PLA/PBS blends with up to 20 weight \% of PBS as the dispersed phase. The viscosity of PLA was significantly higher than that of the PBS and on stretching the blend in the molten state the PBS particles were deformed to produce PBS nanofibres with large aspect ratios. It was concluded that the dispersed PBS droplets became deformed with the PLA in the molten state and coalesced to form fibres; hence the hydrodynamic force overcame the cohesive force on the PBS droplets.

Wu et al [11] reported that blends of PLA and PBS exhibited a phase inversion point of the blend system at a PLA/PBS ratio of 50/50. However, in this case the viscosity of PBS was higher than that of PLA. Hence, this is the reason why a co-continuous phase structure at low additions of PBS was not observed.

Finally, Figure 14 is a schematic diagram of the phase morphologies proposed for the PBS/PLA blends, studied in the current paper, across the full composition range. These morphologies are deduced from the results of tensile testing, AFM, optical microscopy, SEM and melt viscosity studies. Below a composition of 8.4 weight\%, the PBS is dispersed as droplets in a PLA matrix. Above this threshold PBS concentration, there is a co-continuous phase structure of PBS together with PLA, and above 42 weight\% of PBS, the PLA is dispersed as droplets in a matrix of PBS. 


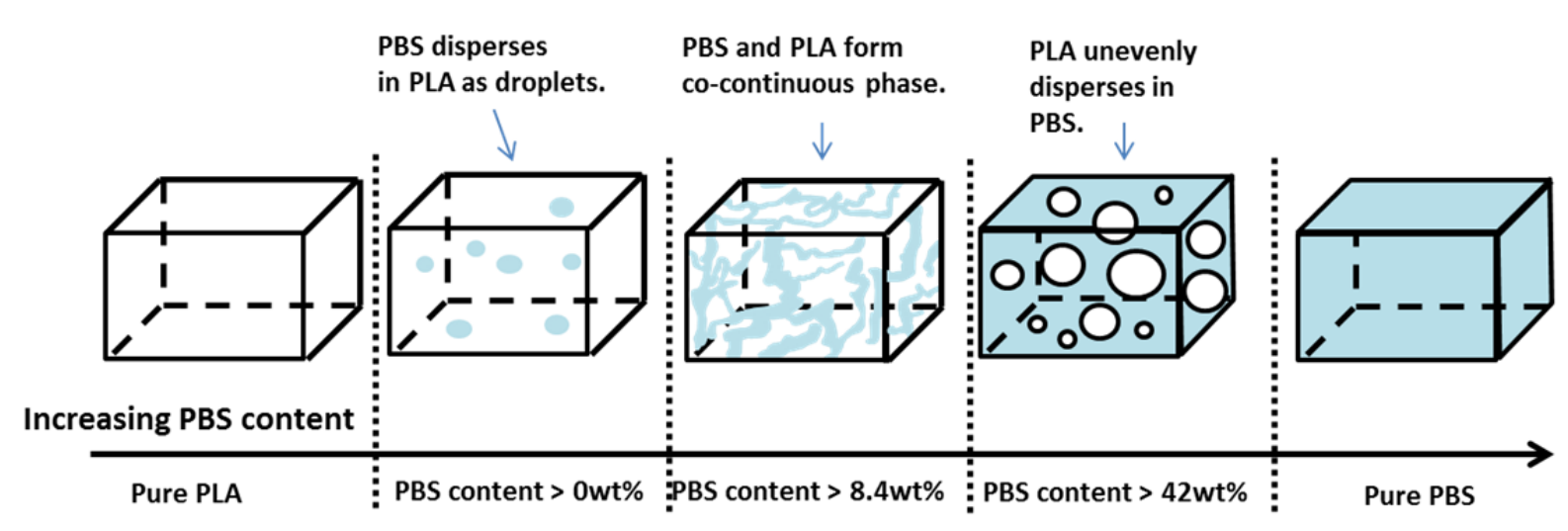

Figure 14. Schematic diagrams of the morphology evolution for PBS/PLA blends. PBS is the shaded part whereas PLA is white.

\section{Conclusions}

A series of melt blended compounds of PBS and PLA were prepared and their thermal properties, crystallinity, melt viscosities, mechanical properties and phase morphology were investigated. It was concluded that PLA and PBS are not substantially miscible because expected reductions in $\mathrm{T}_{\mathrm{g}}$ were not observed. Moreover, all the techniques used to investigate phase morphology (AFM, optical microscopy and SEM) clearly showed a two phase structure. However, a small but significant drop in the $T_{g}$ of the PLA in the PBS/PLA 20/80 blend does indicate some limited miscibility around this composition

In terms of mechanical properties, it was found that Young's modulus and tensile strength both decreased with increasing concentration of PBS, as expected on adding a flexible, ductile polymer to a rigid, brittle polymer. Results for elongation-tobreak showed a dramatic rise: in the composition range of 10 to 40 weight \% of PBS, values of $270 \%$ to $340 \%$ were measured. This result suggested that PBS forms a cocontinuous phase in this composition range.

Phase morphology was invested by AFM, optical microscopy and SEM. All three techniques showed that, in the composition range of $10 \%$ to $40 \%$ PBS, there is a cocontinuous, fibrillar phase structure. At higher composition ranges PBS becomes the sole continuous phase and PLA is dispersed as spheres with a range of particle sizes. These morphologies explain the mechanical properties: the very high ductility in the region of two co-continuous phases dropping when PBS is the matrix with PLA as the dispersed phase.

The reason why PBS forms a continuous phase at very low volume fractions is explained by the relative melt viscosities of PBS and PLA. At a temperature of $175^{\circ} \mathrm{C}$ and a shear strain rate of $47 \mathrm{~s}^{-1}$, the shear viscosities of PBS and PLA were measured to be 162 and 1759 Pa.s respectively. The ratio of the volume fractions at which a co-continuous phase can be formed is equal to the ratio of the viscosities of 
the polymers. The threshold volume fraction ratio for formation of a co-continuous phase structure in this system was calculated to be 0.092 , which is a PBS concentration of 8.4 weight $\%$. This result explains why when blended with as little as 10 weight $\%$ of PBS, the ductility of PLA can be transformed.

\section{Acknowledgements}

The authors would like to acknowledge technical assistance from Dr David Grandy for Atomic Force Microscopy (AFM) and to Mr Jiawei Jin for additional tensile testing data. The authors are also grateful for funding for this work from the Engineering \& Physical Sciences Research Council (EPSRC) and the Department of Materials, Loughborough University.

\section{References}

1. R. Auras, B. Harte, and S. Selke, "An overview of polylactides as packaging materials.," Macromol. Biosci., vol. 4, no. 9, pp. 835-64, 2004.

2. K. M. Nampoothiri, N. R. Nair, and R. P. John, "An overview of the recent developments in polylactide (PLA) research.," Bioresour. Technol., vol. 101, no. 22, pp. 8493-501, 2010.

3. D. Garlotta, "A Literature Review of Poly ( Lactic Acid )," Polym. Environ., vol. 9, pp 63-84, 2002.

4. H. Liu, J. Zhang, 'Research progress in toughening modification poly(lactic acid).,' J Polym Sci B Polym Phys vol.49, no15, pp 1051-83, 2011.

5. B. Imre and B. Pukánszky, "Compatibilization in bio-based and biodegradable polymer blends," Eur. Polym. J., vol. 49, no. 6, pp. 1215-1233, 2013.

6. T. Fujimaki, "Processability and properties of aliphatic polyesters, 'BIONOLLE', synthesized by polycondensation reaction," Polym. Degrad. Stab., vol. 59, pp. 209-214, 1998.

7. T. Miyata and T. Masuko, 'Crystallization behaviour of poly(tetramethylene succinate)', Polymer, 39, pp.1399-1404, 1998.

8. J. W. Park and S. S. Im, "Phase behavior and morphology in blends of poly(Llactic acid) and poly(butylene succinate)," J. Appl. Polym. Sci., vol. 86, no. 3, pp. 647-655, 2002.

9. A. Bhatia, R. K. Gupta, S. N. Bhattacharya, and H. J. Choi, "Compatibility of Biodegradable Poly(lactic acid) (PLA) and Poly(butylene succinate) (PBS) Blends for Packaging Application," Korea-Australia Rheol., vol. 19, no. 3, pp. 125-131, 2007.

10.L. Jompang, S. Thumsorn, J. W. On, P. Surin, C. Apawet, T. Chaichalermwong, N. Kaabbuathong, N. O-Charoen, and N. Srisawat, "Poly(Lactic Acid) and Poly(Butylene Succinate) Blend Fibers Prepared by Melt Spinning Technique," Energy Procedia, vol. 34, pp. 493-499, 2013.

11.D. Wu, L. Yuan, E. Laredo, M. Zhang, and W. Zhou, "Interfacial Properties, Viscoelasticity, and Thermal Behaviors of Poly(butylene succinate)/Polylactide Blend," Ind. Eng. Chem. Res., vol. 51, no. 5, pp. 2290-2298, 2012. 
12.S. Lee and J. W. Lee, "Characterization and processing of Biodegradable polymer blends of poly(lactic acid) with poly(butylene succinate adipate)," Korea-Australia Rheol., vol. 17, no. 2, pp. 71-77, 2005.

13. E. Hassan, Y. Wei, H. Jiao, and M. Yu, "Dynamic Mechanical properties and Thermal stability of Poly(lactic acid) and poly(butylene succinate) blends composites," J. Fiber Bioeng. Informatics, vol. 6, no. 1, pp. 85-94, 2013

14. R. Wang, S. Wang, Y. Zhang, C. Wan, P. Ma, "Toughening Modification of PLLA/PBS Blends via In Situ Compatibization," Polymer Engineering and Science, vol.10, no.2, pp.26-33, 2009.

15. M. Shibata, Y. Inoue, and M. Miyoshi, "Mechanical properties, morphology, and crystallization behavior of blends of poly(l-lactide) with poly(butylene succinate-co-I-lactate) and poly(butylene succinate)," Polymer, vol. 47, no. 10, pp. 3557-3564, 2006.

16. T. Yokohara and M. Yamaguchi, "Structure and properties for biomass-based polyester blends of PLA and PBS," Eur. Polym. J., vol. 44, no. 3, pp. 677-685, 2008.

17. W. Brostow, R. Chiu, I. M. Kalogeras and A. Vassilikou-Dova, "Prediction of glass transition temperatures: Binary blends and copolymers," Mater. Lett., vol. 62, no. 17-18, pp. 3152-3155, 2008.

18. M. Bousmina, A. Ait-kadi and J. B. Faisant, "Determination of shear rate and viscosity from batch mixer data," J. Rheol., vol. 43, no 2, 415, 1999.

19. T. Yokohara, K. Okamoto and M. Yamaguchi, "Effect of the Shape of Dispersed Particles on the Thermal and Mechanical Properties of Biomass Polymer Blends Composed of Poly(L-lactide) and Poly(butylene succinate)" J. Appl. Polym. Sci., vol.117, pp 2226-2232, 2010.

20.Y. J. Shur and B. Ranby, "Gas Permeation of Polymer blends. I. PVC/Ethylene-Vinyl Acetate Copolymer (EVA)," J. Appl. Polym. Sci., vol. 19, pp. 1337-1346, 1975.

21.D. R. Paul and J. W. Barlow, "Polymer Blends," J. Macromol. Sci. Part C Polym. Rev., vol. 18, no. 1, p. 109, 1980.

22. G. M. Jordhamo, J. A. Manson and L. H. Sperling, "Phase Continuity and Inversion in Polymer Blends and Simultaneous Interpenetrating Networks," Polym. Eng. Sci., vol. 26, no. 8, pp. 517-524, 1986.

23. D. R. Paul, 'Polymer Blends: Phase Behaviour and Property Relationships', Chapter 1 in 'Multicomponent Polymer Materials', D. R. Paul and L. H. Sperling, Eds, Advances in Chemistry, American Chemical Society: Washington, DC, 1985.

24. M. Han, W. Seo, H. Paik, J. Hyun, J. Lee and W. Kim, "Rheological Properties and Phase Inversion of Polypropylene and Poly (styrene-co-acrylonitrile ) Blends," Polym. J., vol. 35, no. 2, pp. 127-132, 2003. 